\title{
Toplum Kaynaklı Üriner Enfeksiyon Etkeni Escherichia coli Suşlarında Antibiyotik Direnci
}

\section{Antimicrobial Resistance of Escherichia coli Strains in Community Acquired Urinary Tract Infections}

Recep Alanlı $^{1}$ ORCID No: 0000-0003-4663-1898, Bülent Ahmet Beşirbellioğlu ${ }^{2}$ ORCID No: 0000-0003-2172-0616, Gültekin Çelik ${ }^{2}$ ORCID No: 0000-0002-2746-3297

${ }^{1}$ Lokman Hekim Üniversitesi Tıp Fakültesi, İç Hastalıkları Anabilim Dalı, Ankara, Türkiye.

${ }^{2}$ Lokman Hekim Üniversitesi Tıp Fakültesi, Enfeksiyon Hastalıkları Anabilim Dalı,Ankara Türkiye.

Geliş Tarihi/Received: 01.03.2021

Kabul Tarihi/Accepted: 08.04.2021

Yazışma Adresi/Address for

Correspondence:

Recep Alanlı

Lokman Hekim Üniversitesi

Tıp Fakültesi,

İç Hastalıkları Anabilim Dalı,

Andiçen Mah. İdil Sk. No: 44

Sincan, Ankara, Türkiye.

e-posta: recepalanli@gmail.com

\section{Anahtar Sözcükler:}

Antibiyotik direnci

Escherichia coli

Üriner enfeksiyon

\section{Key Words:}

Antibiotic resistance

Escherichia coli

Urinary tract infection

\section{öz}

Amaç: Antibiyotik direnci önemli bir sağlık problemidir ve sağlık sistemi üzerine yaptığı olumsuz etkiler gün geçtikçe artmaktadır. Bu çalışmada; toplum kaynaklı üriner sistem enfeksiyonu etkeni Escherichia coli suşlarının antibiyotiklere direnç oranları incelendi.

Gereç ve Yöntem: Temmuz 2019 ile Haziran 2020 arasında; toplum kaynaklı üriner sistem enfeksiyonu etkeni olarak E. coli üremesi saptanan 494 hastanın antibiyogram sonuçları ve demografik özellikleri retrospektif olarak değerlendirildi.

Bulgular: E. coli'nin antibiyotiklere gösterdiği direnç oranları, en azdan en çok olana doğru sırasıyla; amikasin $(\% 0,4)$, tigesiklin (\%2), imipenem (\%2), meropenem (\%2), sefiksim (\%32), seftriakson (\%29) ve trimetoprim-sülfametaksazol (\%28) olarak saptandı.

Sonuç: Toplumdan edinilmiş üriner sistem enfeksiyonlarında ampirik olarak; oral fosfomisin veya nitrofurantoin ya da günde tek doz intramusküler amikasin kullanılmasının akılcı olacağı, öte yandan; sefiksim, trimetoprim-sülfametaksazol, siprofloksasin ve sefuroksim kullanılırken, yüksek antibiyotik direnci nedeniyle dikkatli olunması gerektiği düşünülmektedir.

\section{ABSTRACT}

Objective: Antibiotic resistance is one of the most important health problem and its negative impact on global health is increasing day by day. In this study, antibiotic resistance of Escherichia coli strains that cause community acquired urinary tract infections were evaluated.

Material and Method: Demographic characteristics, urinary cultures and antibiotic susceptibility tests of 494 patients for Escherichia coli, as community acquired urinary tract infection etiology were evaluated retrospectively between July 2019 and June 2020.

Results: Resistance rate of E. coli strains to antibiotics from lowest to highest were found to be; amikacin $(0.4 \%)$, imipenem $(2 \%)$, meropenem $(2 \%)$, fosfomycine $(4 \%)$, nitrofurantoin (4\%), ceftazidim (9\%), amoxicillin/clavulonic acid (13\%), ciprofloxacin (22\%), trimethoprim-sulfamethoxazole (28\%), ceftriaxsone (29\%) and cefixime (32\%).

Conclusion: The useage of oral fosfomycin or nitrofurantoin or intravascular amikacin in the empirical treatment of community acquired urinary tract infections is a reasonable option. On the other hand, cefixime, trimethoprim-sulfamethoxazole, ciprofloxacin and cefuroxime should be used as second-line drugs due to their high resistance rates. 


\section{हHMJ}

\section{Giriş}

Üriner sistem enfeksiyonu (ÜSE), klinik belirtilerle birlikte idrarda anlamlı miktarda bakteri saptanmasıdır. Dünyada her yıl 150 milyon ÜSE geliştiği ve ÜSE nedeniyle 6 milyar dolardan fazla direkt sağıık harcaması gerçekleştiği bildirilmiştir (1). ÜSE ayaktan başvuran hastalarda en sık saptanan enfeksiyon tipidir (2). ÜSE'de en sık saptanan etken ise bağırsak florasında bulunan Escherichia coli'dir (3).

Antibiyotik direnci, önemi gittikçe artan bir sağlık problemidir. Dirençli bakteri enfeksiyonları birçok ülkede sürekli artmakta olup, 2050 yılında, bir yılda 10 milyon kişide antibiyotik dirençli enfeksiyon gelişeceği tahmin edilmektedir (4). Eylül 2016'da; Birleşmiş Milletler'e üye 193 ülke dirençli bakteriler ve direncin yayılması ile mücadelede ortak hareket etme kararı almıştır (5).

ÜSE, birinci basamak tedavi hizmetlerinde en sık antibiyotik direnci gözlenen enfeksiyon tipidir (6). ÜSE tedavisinde genelde ampirik antibiyotik kullanılmaktadır ve E. coli' de saptanan antibiyotik direnci önemli bir sağlık problemi olarak önümüzde durmaktadır (7). Bu vakalarda ampirik tedavinin sık kullanılması, birinci basamakta, hatta bazen ikinci basamakta kültür antibiyogram imkanlarının kısıtlı veya zaman alıcı olmasından kaynaklanmaktadır. Bu yüzden E. coli'nin antibiyotik duyarlıığını bilmek, en uygun ilacın seçilmesine yardımcı olarak, tedavi başarısını arttıracaktır.

Bu çalışmada, hastanemize üriner sistem enfeksiyonu belirtileri ile başvuran ve toplumdan edinilmiş ÜSE saptanan hastalara ait idrar örneklerinden izole edilen E. coli suşlarının antibiyotiklere direnç oranlarını incelemek hedeflenmiştir.

\section{Gereç ve Yöntem}

Temmuz 2019 ile Haziran 2020 tarihleri arasında üçüncü basamak olan hastanemize ayaktan başvuran ve toplum kaynakı ÜSE tanısı konularak idrar kültürü alınan ve E. coli üremesi saptanan 494 hastanın antibiyogram sonuçları ve demografik özellikleri retrospektif olarak değerlendirildi. Çalışma için Lokman Hekim Üniversitesi Etik Kurulundan 26.06.2020 tarih ve 2020/049 numaralı kararı ile etik onay alınmıştır.

Yapısal veya fonksiyonel genitoüriner sistem patolojisi olanlar, gebeler, diabet hastalığı, sürekli veya aralıklı idrar katateri olan hastalar, böbrek ve karaciğer yetmezliği, bağışıkıı̆ı baskılanmış ve kanser hastalığı olanlar ile hastaneye yatıştan 48 saat sonra ÜSE saptanan hastalar çalışmaya alınmadı.
Hastalardan uygun temizlik ve antisepsi sonrası, alınan steril orta akım idrar örnekleri 0,4 mm çapındaki kalibre öze ile \%5 koyun kanlı agar ve eozin metilen mavisi agar besi yerlerine ekildi. Örnekler aerop koşullarda $37^{\circ} \mathrm{C}$ de 24 48 saat süreyle inkübe edildi. Besiyerinde $10^{5} \mathrm{CFU} / \mathrm{mL}$ 'den fazla üreme gösteren gram negatif bakteriler, konvansiyonel yöntemlerle tanımlandı. Antibiyotik duyarlılık testi disk difüzyon yöntemiyle güncel "Klinik ve Laboratuvar Standardları Enstitüsü (CLSI) kriterlerine göre yapıldı. Antibiyotik duyarlılık testinde kullanılan diskler ve içerikleri;

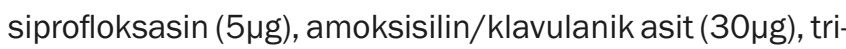

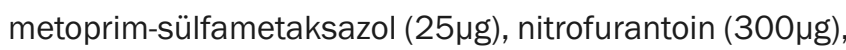

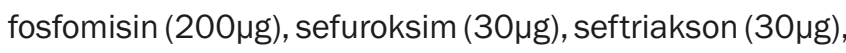

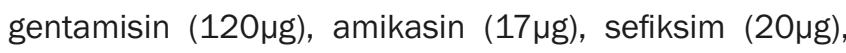

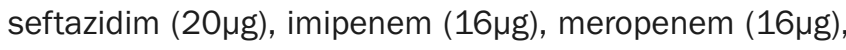
piperasilin-tazobaktam $(21 \mu \mathrm{g})$ ve tigesiklin $(20 \mu \mathrm{g})$ idi. BD BBL Sensi-Disc (USA) marka antibiyotik diskleri kullanıldı. Zon çapları CLS kriterlerine göre değerlendirildi.

Verilerin istatiksel analizi SPSS 25 programı kullanılarak değerlendirilmiştir (SPSS Inc., Chiago, IL, USA). Veriler ortalama \pm standart sapma olarak ifade edilmiştir. Çalışmada, $\mathrm{P}<0,05$ olduğunda sonuçlar ististatiksel olarak anlamlı kabul edilmiştir.

\section{Bulgular}

Çalışmaya alınan 494 hastanın, 71 (\%14)'i erkek, 423 (\%86)'ü kadınlardan oluşmaktaydı. Hastaların ortalama yaşı 40,29 $\pm 28,87$ (erkeklerin $45,87 \pm 29,92$, kadınların $39,36 \pm 28,61$ ) idi. Çalışmaya alınan hastaların 262 (\%53)'sinde E. coli tüm antibiyotiklere duyarlı olarak saptandı. E. coli suşlarının en duyarlı olduğu antibiyotikler ve direnç oranları şunlardır; amikasin $(\% 0,4)$, tigesiklin (\%2), imipenem (\%2) ve meropenem (\%2). En yüksek direnç saptanan antibiyotiklerdeki direnç oranları ise sırasıyla; sefiksim (\%32), seftriakson (\%29) ve trimetoprim-sülfametaksazol (\%28) olarak saptanmıştır. E. coli suşlarının antibiyotik direnç oranları Tablo 1'de gösterilmiştir.

Kadın hastalar, ÜSE sıkığını incelemek için yaşlarına göre iki gruba ayrılmış ve 274 (\%65) hastanın premenapozal, 149 (\%35)'ünün ise postmenapozal dönemde olduğu saptanmıştır.

\section{Tartışma}

Dünyanın birçok bölgesinden yapılan çalışmalarda ÜSE'de kullanılan antibiyotiklere karşı direnç oranlarında artış bildirildiği için ampirik tedavide kullanılacak antibiyo- 
tiklerin bu direnç oranlarına göre belirlenmesi önerilmektedir (8). ÜSE'nin ampirik tedavisinde, \%20'den fazla direnç saptanan antibiyotiklerin kullanılmaması tavsiye edilmektedir (9). Bu yüzden tedavi başlamadan önce mevcut antibiyotiğin E.coli'ye direnç oranını bilmek önem arzetmektedir.

Tablo 1: E. coli suşlarının antibiyotik direnç oranları.

\begin{tabular}{lcc}
\hline Antibiyotik & $\begin{array}{c}\text { Dirençli suş } \\
\text { sayıs (n) }\end{array}$ & $\begin{array}{c}\text { Yüzde } \\
(\%)\end{array}$ \\
\hline Sefiksim & 157 & 32 \\
Seftriakson & 143 & 29 \\
Trimetoprim-sülfametaksazol & 138 & 28 \\
Siprofloksasin & 107 & 22 \\
Sefuroksim & 107 & 22 \\
Amoksisilin/klavulanik asit & 63 & 13 \\
Seftazidim & 45 & 9 \\
Gentamisin & 33 & 7 \\
Nitrofurantoin & 21 & 4 \\
Fosfomisin & 20 & 4 \\
Piperasilin tazobaktam & 18 & 4 \\
Meropenem & 11 & 2 \\
Imipenem & 10 & 2 \\
Tigesiklin & 10 & 2 \\
Amikasin & 2 & 0,4 \\
\hline
\end{tabular}

ÜSE kadınlarda daha sık saptanmaktadır. En sık ÜSE etkenleri de bağırsak florasında bulunan bakterilerden olan E. coli'dir. ÜSE'nin kadınlarda daha sık saptanmasının, kadınlarda üriner sistemin kolonizasyona izin verecek şekilde daha kısa olması ile ilgili olduğu düşünülmektedir (10). Çalışmamızda; E. coli saptanan, toplum kaynaklı ÜSE hastalarının \%86'sı kadınlardan oluşmaktaydı.

Nitrofurantoin komplike olmayan ÜSE'de ilk tercih edilebilecek antibiyotiklerdendir (9). Nitrofurantoin sadece ÜSE'de kullanılan, dağılım hacmi fazla olmayan, seruma çok düşük oranda geçen ve etki spektrumu dar olan bakterisidal etkili bir antibiyotiktir (11). Ancak nitrofurontain alerji, intolerans ve böbrek fonksiyonlarında bozulma durumlarında kullanılmamaktadır. Türkiye'de yapılan bir çalışmada E. coli'nin nitrofurantoin direnci \%5,3 olarak bulunmuştur (3). Yapılan bu çalışmada nitrofurantoin direnci $\% 4$ olarak bulunmuştur. Bu nedenle E. coli'nin ampirik tedavisinde birinci tercih olarak nitrofurontain kullanımasının uygun olacağı düşünülmüştür.

Fosfomisin idrara yüksek oranda geçen ve bakterisidal etkili bir fosfonik asit türevidir (12). Türkiye'de yapılan bir çalışmada E. coli'nin fosfomisin direnci \%0,3 saptanmıştır
(13). Bizim çalışmamızda fosfomisin direnci bu değere yakın bulunmuştur. Bu nedenle E. coli'nin ampirik tedavisinde birinci tercih olarak fosfomisinin de kullanılması da uygun olabilir.

Bir çalışmada E. coli'nin siprofloksasin direnci \%17 olarak bulunmuştur (13). Brezilya'da 1641 idrar örneği ile yapılan bir çalışmada E. coli'nin siprofloksasin direnci 2010 yılında \%16 iken 2014 yılında \%36'ya yükselmiştir (14). İrlanda'da yapılan bir çalışmada 2005-2014 yılları arasında toplam $15695 \mathrm{E}$. coli üremesi saptanmıştır. Bu sürede; siprofloksasin, amoksisilin/klavulanik asit, trimetoprim-sülfametaksazol ve piperasilin-tazobaktam direnci artmış, gentamisin ve nitrofurantoin direncinde anlamlı bir değişiklik saptanmamıştır (15). Çalışmamızda siprofloksasin direnci \%22 olarak bulunmuştur. Bu Türkiye'de daha önce yapılan çalışmalara göre daha yüksek bir orandır (13, 16). Siprofloksasinin ayaktan ampirik tedavide sık kullanılması nedeniyle direnç gelişiminde artış olduğu düşünülmektedir. Bu bağlamda, toplumdan edinilmiş ÜSE tedavisinde ampirik antibiyotik seçiminde siprofloksasinin daha dikkatli kullanılması ve tedavi başarısızlığı ile karşılaşılabileceğinin bilinmesi gerektiğini düşünmekteyiz.

İran'da yapılan bir çalışmada E. coli'nin seftazidim direnci $\% 17$ saptanırken, imipeneme $\% 3$ direnç saptanmış, amikasine ise direnç saptanmamıştır (17). Çalışmamızda sefiksim, seftriakson, sefuroksim ve seftazidim direnci yüksek saptanmıştır. Avusturalya'da yapılan bir çalışmada ÜSE'de sefalosporinlere karşı gelişen yüksek direnç oranı nedeniyle ampirik tedavide bu grubun kullanılmaması önerilmektedir (18). Biz de E. coli tedavisinde sefalosporinlerin uygun bir seçenek olmadığını düşünmekteyiz. Çünkü, üçüncü kuşak bir sefalosporin olan ve Gram (-) etkinliğinin çok yüksek olması beklenen "sefiksim"e dahi, çalışmamızdaki suşların üçte biri dirençli bulunmuştur. Bu kadar yüksek direncin olası nedeninin; "özellikle çocuk yaş grubunda kinolonlar yerine tercih edilebilen ve Gram (-) etkinliği yüksek bir üçüncü kuşak sefalosporin olması ve bu yüzden de ayaktan hastalarda sıklıkla reçete ediliyor olması" olduğunu değerlendirmekteyiz.

Türkiye'de yapılan bir çalışmada ÜSE'de E. coli'nin trimetoprim-sülfametaksazol direnci \%36 olarak saptanmıştır (13). Başka bir çalışmada ise trimetoprim-sülfametaksazol direnci \%45 olarak bulunmuştur (15). Çalışmamızda da E. coli'nin trimetoprim-sulfametaksazol direnci yüksek saptanmıştır. Bu yüzden trimetoprim-sülfametaksazol sadece duyarlıı̆̆ı yüksek bulunan antibiyotikler kullanılamadığı zaman verilmesinin uygun olacağı düşünülmüştür. 


\section{数HMJ}

Türkiye'de yapılan bir çalışmada, amoksisilin/klavulanik asite direnç \%26 olarak bulunmuştur (13). İrlanda'da yapılan başka bir çalışmada ise amoksisilin/klavulanik asit direnci \%32 bulunmuştur (15). Amoksisilin/klavulanik asit; oral kullanımı olan, yan etkilerinin çok seyrek görüldüğü, her yaş ve hasta grubunda (yeni doğanlar ve gebeler dahil) güvenle kullanılabilen bir antibiyotik olduğu göz önünde bulundurulmakla beraber, çalışmamızda direnç oranının kritik bir seviyede saptandığını bildirir ve hastanemizde kullanırken dikkatli davranılması gerektiğini düşünmekteyiz.

Çalışmamızda; piperasilin-tazobaktam, karbapenemler ve tigesiklin dirençleri düşük bulunmuştur. Bunun olası nedeni olarak bu antibiyotiklerin oral formlarının bulunmaması ve ayaktan hastalara sıklıkla reçete edilememesi olduğunu düşünmekteyiz. Bu şekilde devam etmesinin faydalı olduğuna inanıyoruz. Çünkü bilindiği üzere bunlar çok geniş spektrumlu antibiyotikler olup, dirençli hastane enfeksiyonları dışında kullanılmamaları gerektiği bilimsel kaynaklarda ifade etmektedir.

Türkiye'de yapılan bir meta-analizde 1996 ile 2012 yıllarındaki makaleler taranmış ve bu süre zarfında nitofu-

Yazarlık Katkısı: Fikir/Hipotez: RA, BAA Tasarım: RA, BAA, GÇ Veri toplama/Veri işleme: RA, GÇ, BAA. Veri analizi: RA, BAA Makalenin hazırlanması: RA, GÇ, BAA Makalenin kontrolü: RA, BAA, GÇ

Etik Kurul Onayı: Lokman Hekim Üniversitesi Girişimsel Olmayan Etik Kurulundan 26.06.2020 tarih ve 2020/049 numaralı kararı ile alınmıştır. Çalışma Helsinki Deklarasyonu'na uygun olarak yürütülmüştür.

Hasta Onayı: Hastaların tümünden çalışmaya katılmaları için onam alınmıştır.

\section{Kaynaklar}

1. Stamm WE, Norrby RS. Urinary tract infections: disease panorama and challenges. J Infect Dis 2001;183:1-4.

2. Auer S, Wojna A, Hell M. Oral treatment optionsfor ambulatory patients with urinary tract infections caused by extendedspectrum-ß-lactamase producing Escherichia coli. Antimicrob Agent Chemother 2010;54:4006-8.

3. Coşkun Ö, Erdem H, Avcı A. Management of community-acquired acute bacterial cystitis in Turkey. Turk J Med Sci 2011;4:149-57.

4. O'Neill J. Tackling Drug-Resistant Infections Globally: Final Report and Recommendations. http://amr-review.org/sites/default/ files/160525_Final \%20paper_with\%20cover.pdf.

5. UK Department of Health. UK Secures Historic UN Declaration on Antimicrobial Resistance. https://www.gov.uk/government/ news/uk-secureshistoric-un-declaration-on-antimicrobialresistance. rantoin ve piperasilin direncinde azalma; siprofloksasin, sefepim, trimetoprim-sülfametaksazol ve beta-laktam direncinde ise artış saptanmıştır (19). Bu sonuçlar yapılan bu çalışma ile benzerdir.

Sonuç olarak toplumdan edinilmiş ÜSE'de ampirik olarak oral fosfomisin veya nitrofurantoin ya da kas içerisine günde tek doz amikasin kullanılması daha akılcı olacaktır. Ancak yüksek direnç oranı nedeniyle sefiksim, trimetoprimsülfametaksazol, siprofloksasin ve sefuroksim kullanılırken dikkatli olunması ve başarı oranının düşük olabileceğinin unutulmaması gerektiği düşünülmektedir. Ayrıca; E. coli direncinde artışlar bildirildiği için, tüm sağlık birimlerinde tedavi öncesi idrar kültürü ve antibiyogram çalışılmasının pratik bir alışkanlık haline getirilmesi ve bu yönde imkan varsa ileri teknolojiler de kullanılarak klinisyen hekimlerin laboratuvar olarak desteklenmesi en doğru yaklaşım olacaktır.

Teşekkür: Yazarlar idrar örnekleri incelemesinde katkı sağlayan laboratuar ekibine ve istatiksel analiz için Fatih Açıkgöz'e teşekkür ederler.

Hakem Değerlendirmesi: ilggili alan editörü tarafından atanan iki farklı kurumda çalışan bağımsız hakemler tarafından değerlendirilmiştir.

Çıkar Çatışması: Yazarlar tarafından çıkar çatışması bildirilmemiştir.

Finansal Destek: Yazarlar tarafından finansal destek almadıkları bildirilmiştir.

6. Chin TL, MacGowan AP, Bowker KE, Elder F, Beck CR, McNulty C. Prevalence of antibiotic resistance in Escherichia coli isolated from urine samples routinely referred by general practitioners in a large urban centre in South-west England. J Antimicrob Chemother 2015;70:2167-9.

7. Hooton TM, Besser R, Foxman B, Fritsche TR, Nicolle LE. Acute uncomplicated cystitis in an era of increasing antibiotic resistance: A proposed approach to empirical therapy. Clin Infect Dis 2004;39:75-80.

8. Köken G, Aşık G, Çiftçi iH, Çetinkaya Z, Aktepe OC, Yılmazer M. Toplum kökenli üriner sistem infeksiyonu etkeni Escherichia coli suşlerında fosfomisin trometamol etkinliği. ANKEM Derg 2008;22:23-27. 
9. Gupta K, Hooton TM, Naber KG et al. International clinical practice guidelines for the treatment of acute uncomplicated cystitis and pyelonephritis in women: a 2010 update by the Infectious Diseases Society of America and the European Society for Microbiology and Infectious Diseases. Clin Infect Dis 2011;52:103-120.

10. Mazzulli T. Antimicrobial resistance trends in common urinary pathogens. Can J Urol 2001;8:2-5.

11. Hooper DC. Urinary tract agents: nitrofurantoin and methenamine. In: Mandell GL, Bennett JE, Dolin R, eds. Mandell, Douglas, and Bennett's principles and practice of infectious diseases. 5th ed. Vol 1. Philadelphia: Churchill Livingston, 2000:423-8.

12. Neu HC. Fosfomycin Trometamol versus Amoxycillin - single dose multicenter study of urinary tract infections. Chemotherapy 1990;36:19-23.

13. Arslan H, Azap OK, Ergönül O, Timurkaynak F. Risk factors for ciprofloxacin resistance among Escherichia coli strains isolated from community-acquired urinary tract infections in Turkey. J Antimicrob Chemother 2005; 56:914-8.
14. Reis AC, Santos SR, Souza SC, Saldanha SC, Pitanga TN, Oliveira RR. Ciprofloxacin resistance pattern among bacteria isolated from patients with community-acquired urinary tract infection. Rev Inst Med Trop Sao Paulo 2016;58:53.

15. Stapleton PJ, Lundon DJ, McWade R, ve ark. Antibiotic resistance patterns of Escherichia coli urinary isolates and comparison with antibiotic consumption data over 10 years, 2005-2014. Ir J Med Sci 2017;186:733-41.

16. Şahin I, Şencan I, Kaya D, Gülcan A, Öksüz Ş. Hastane infeksiyonu etkeni üropatojen Escherichia coli izolatlarının çeşitli antibiyotiklere direnç durumu. ANKEM Derg 2004;18:193-5.

17. Shams S, Hashemi A, Esmkhani M, Kermani S, Shams E, Piccirillo A. Imipenem resistance in clinical Escherichia coli from Qom, Iran. BMC Res Notes 2018;11:314.

18. Mehr SS, Powell CVE, Curtis N. Cephalosporin resistant urinary tract infections in young children. J Paediatr Child Health 2004;40:48-52.

19. Aykan SB, Ciftci IH. [Antibiotic resistance patterns of Escherichia coli strains isolated from urine cultures in Turkey: a metaanalysis]. Mikrobiyol Bul 2013;47:603-18. 